\title{
EFFECTS OF BALANCING RICE BRAN BASED DIETS FOR UP TO FOUR AMINO ACIDS ON GROWTH PERFORMANCE OF BROILERS
}

\author{
MKDK Piyaratne ${ }^{1}$, NSBM Atapattu ${ }^{2 *}$, APS Mendis ${ }^{2}$ and AGC Amarasinghe ${ }^{2}$ \\ ${ }^{1}$ Computer Unit, Faculty of Agriculture, University of Ruhuna, Mapalana, Kamburupitiya \\ ${ }^{2}$ Department of Animals Science, Faculty of Agriculture, University of Ruhuna, Mapalana, Kamburupitiya
}

Accepted: $30^{\text {th }}$ September 2009

\begin{abstract}
Objective of this study was to determine whether the adverse effects associated with high dietary rice bran (RB) inclusion levels in broiler diets could be corrected by balancing diets for higher number of amino acids (AA). The experiment followed a completely randomize design in $2 \times 4$ factorial arrangement. Eight experimental diets were formulated using linear model based computer software (CUFATotal Feed). Treatment factors were two dietary RB levels $(20$ and $40 \%)$ and four levels of $A A$ considerations in ration formulation (1. lysine and methionine, $2.1+$ isoleucine, 3. $2+$ valine, $4.3+$ threonine). When rations were balanced for lysine and methionine, many of the other AAs were in excess. No practical ration could be formulated to meet the threonine requirement. Twenty-two-day old broiler chicks $(n=144)$ were allocated into 48 pens and fed one of the eight experimental diets ad libitum from 23-43 days. Balancing the diets for higher number of AAs had no significant effect on any of the growth performance parameters. Live weight on day 43, weight gain from day 23-43 and feed intake and the tibia ash contents of the broiler fed $40 \%$ dietary RB were significantly lower than those of $20 \%$ RB fed counterparts. However, feed conversion ratios were not significantly different between the birds fed two dietary RB levels. Interaction between RB levels and the number of AAs considered in ration formulation was not significantly different with respect to any of the growth parameters measured. It was concluded that balancing rations for up to four amino acids; lysine, methionine, isoleucine and valine did not mitigate the adverse effects of $\mathbf{4 0 \%}$ dietary $\mathrm{RB}$ in broiler growth performance.
\end{abstract}

Key words: Amino acids, Broiler performance, Rice bran

\section{INTRODUCTION}

Rice bran is one of the major ingredients used in poultry feed formulations. Even though the in vitro nutritive value of RB is comparable with other cereals and their by-products, its in vivo nutritive value is inferior, mainly due to the presence of a range of anti-nutrients such as phytate, fibre, lipases and anti-proteolytic substances. As the RB is cheap and locally available, the price of poultry feed can be reduced substantially if higher $\mathrm{RB}$ levels can be included in poultry diets. However, more than $20 \%$ $\mathrm{RB}$ in broiler diets reduces the performance and mineral status of the birds while increasing the mineral excretion (Warren and Farrell 1990). General$1 y$, in ration formulation, only the lysine and methionine is considered. As protein value of RB is low due to the presence of phytase, fibre and antiproteolytic substances (Selle et al. 2000), other amino acids can easily be limiting, particularly when higher levels of RB are included in poultry diets. Apart from lysine and methionine, other AAs such as isoleucine, valine and threonine are also low in RB. It is hypothesized that balancing of diets for more AAs namely lysine, methionine, isoleucine, valine and theronine would mitigate the adverse affects of higher $\mathrm{RB}$ inclusion levels on growth performance of broiler chicken. The present study tests the above hypothesis.

\section{MATERIALS AND METHODS}

Broiler chicks (Hybro $\mathrm{PG}+$ ) were brooded in an electrically heated floor brooder until day 10 . Until day 22 , birds were fed a commercial broiler starter diet. On day 22, chicks $(n=144)$ were weighed and allocated into 48 pens hence live weight variation between pens were minimum. Pens $(75 \mathrm{~cm}$ x $60 \mathrm{~cm}$ $\mathrm{x} 60 \mathrm{~cm}$ ) were randomly allocated into eight dietary treatments arranged into $2 \times 4$ factorial arrangement. Eight nutritionally balanced diets were formulated using linear model based computer software (CUFATotal Feed) (Table 1). Treatment factors were two dietary RB levels (20 and $40 \%$ ) and four levels of AA considerations in ration formulation 1. lysine and methionine (LM), 2. lysine, methionine and isoleucine (LMI), 3. lysine, methionine + isoleucine and valine (LMIV), 4. lysine, methionine + isoleucine valine and threonine (LMIVT). Digestible amino acid contents of the feed ingredients were considered in ration formulation. Birds were fed experimental diets and water ad libitum from day 23-43. Cage-wise daily feed

\footnotetext{
*Corresponding author: nsbm@ansci.ruh.ac.lk

Paper presented at the $2^{\text {nd }}$ National Symposium, Faculty of Agriculture, University of Ruhuna
} 
intake and the live weights of the birds were determined weekly. On day 43, tibia of a randomly selected bird from each cage were removed and used to determine the fat free tibia ash contents. Data were analyzed using GLM procedure of statistical software SAS (1989). Main effects were considered significant when $\mathrm{P}<0.05$ and when interactions were significant, LS mean comparison was performed to compare the means.

\section{RESULTS}

\section{Ration composition}

The ingredient composition and calculated nutrient composition of the diets are shown in Table 1.

The maize meal level reduced with increasing dietary RB inclusion level. The levels of sesame meal and soybean meal changed in an erratic manner across the diets.

\section{Growth performance and carcass parameters}

Effects of two dietary rice bran levels and balancing the diets for up to four AAs on growth performance and carcass parameters of broiler chicken are shown in Table 2 and 3. Performance parame- ters such as live weight on day 30,37 and 43 , weight gain from day 23-30 and total weight gain from day 21-43 and feed intake were significantly low for the birds fed $40 \% \mathrm{RB}$, compared to those fed $20 \%$ RB. Feed conversion ratio was not significantly affected by the dietary RB levels. None of the growth performance parameters was significantly affected by the number of AAs for which the rations were balanced.

Tibia ash content was also significantly lower when $40 \%$ RB was fed. The relative weight of the liver and the fat were significantly reduced at $40 \%$ dietary RB level.

None of the growth performance or carcass parameters was significantly affected by the interaction between the RB level and the number of AAs for which the rations were balanced.

\section{DISCUSSION}

\section{Ration formulation and composition}

Given the complex specifications required in the nutrient composition of the rations, it was not possible to maintain the ingredient composition similar across the eight rations formulated. At both RB levels, to balance the rations for threonine, the fish

Table 1: Ingredient composition and calculated nutrient composition of the experimental diets

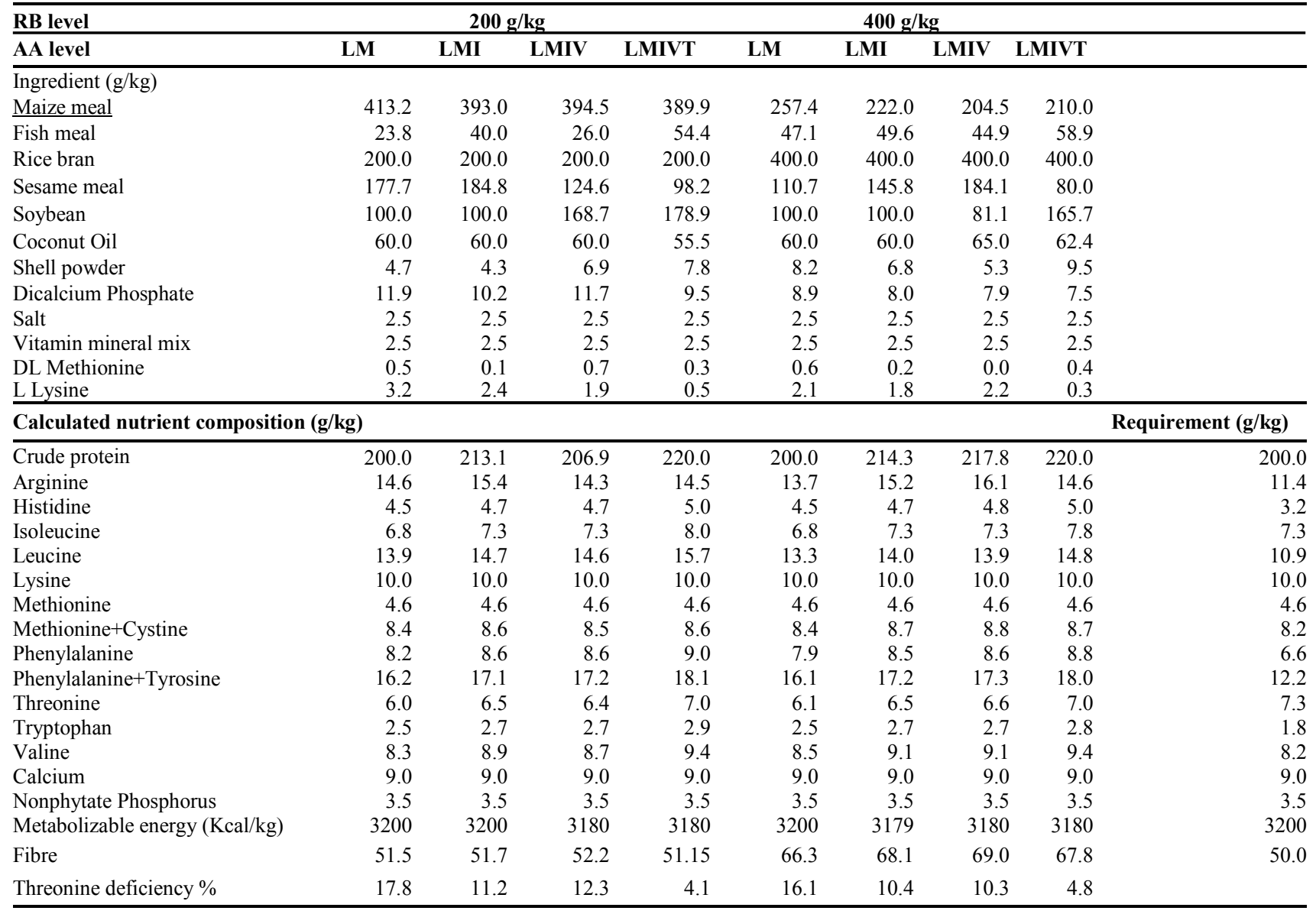


meal level had to increase. The percentage deficiency of threonine, compared to the required level varied from $4-18 \%$ (Table 1). Of the five AAs considered in the ration formulation, threonine was considered last after methionine, lysince, isoleucine and valine. Difficulty of balancing the ration for threonine suggests that, threonine should have been considered before isoleucine and valine. Fernandez et al. (1994) and Kidd and Kerr (1996) showed that threonine was the third limiting amino acid of broilers fed corn-soybean based diets. The rations of this experiment were based on corn, RB, sesame and soybean. Nutrient compositions of the formulated rations suggest that threonine could be the third limiting amino acid in broiler rations based on the above ingredients as well. Even the diet balanced for LMIV with $20 \% \mathrm{RB}$ was deficient in threonine. Kidd (2000) reported that threonine deficiency resulted in decreasing utilization of sulfur amino acids and lysine. Except one (LMIVT; 20\% RB) all other rations exactly met the lysine requirement. The levels of methionine and cystein were also just above the required level. Therefore, it can be assumed that threonine was the limiting amino acid under the present experimental conditions. The results of this experiment highlight the importance of balancing the broiler rations for threonine.

At both RB levels, formulation of the diets for more amino acids increased the dietary crude protein contents as well. However, as discussed below, high dietary Crude Protein contents had no beneficial effects on growth performance.

\section{Growth performance}

In general, growth performance parameters were significantly lower for the broilers fed $40 \%$ dietary $\mathrm{RB}$ than those fed $20 \% \mathrm{RB}$. Adverse effects of higher dietary RB levels in broiler diets are well documented (Atapattu and Gamage 2007; Warren and Farrell 1990; Farrell and Martin 1998a; Martin et al. 1998). Rice bran contains a range of antinutrients such as phytates, fibre and anti-proteolytic substances known reduce the in vivo nutritive value of rice bran and thereby the performance of broilers when fed at higher levels. Week-wise analysis of growth performance revealed that negative effects of $40 \%$ dietary RB on weight gain and feed conversion ratio became significant during the first week of treatment imposition. Similarly, feed intake was not significantly reduced after day 37 . These findings suggest that adverse effects of high dietary RB levels may diminish as birds become mature. Mature broilers may have relatively better anatomical and physiological mechanisms to cope up with antinutrients such as phytate, fibre and anti-proteolytic substances. Farrell and Martin (1998b) also found that older ducks performed better with higher dietary RB levels than young ducks.

The final Feed Conversion Ratio of the birds fed $40 \%$ (1.953) dietary RB was similar to that of the birds fed $20 \%$ RB (1.957). Since the cost of formulations can substantially be reduced by increasing the level of RB in the diet, the actual feeding value of higher dietary RB levels should better be compared on gain per unit feed cost basis than on direct growth parameters such as weight gain and live weight.

Table 2: Effects of two dietary rice bran levels and balancing the diets for up to four amino acids on the growth performance of broiler chicken

\begin{tabular}{|c|c|c|c|c|c|c|c|c|c|c|c|c|}
\hline \multirow{2}{*}{$\begin{array}{l}\text { RB level } \\
\mathbf{A A}\end{array}$} & \multicolumn{3}{|l|}{$20 \%$} & \multicolumn{4}{|c|}{$40 \%$} & \multicolumn{3}{|c|}{ Probability } & \multirow[b]{2}{*}{$\mathbf{A A}$} & \multirow[b]{2}{*}{$\mathbf{R B} * \mathbf{A} \mathbf{A}$} \\
\hline & $\mathbf{L M}$ & LMI & LMIV & LMIVT & $\mathbf{L M}$ & LMI & LMIV & LMIVT & SEM & RB & & \\
\hline \multicolumn{13}{|c|}{ Live weight (g) } \\
\hline $23 \mathrm{~d}$ & 1061 & 1061 & 1046 & 1069 & 1054 & 1059 & 1047 & 1062 & 5.9 & NS & $*$ & NS \\
\hline $30 \mathrm{~d}$ & 1420 & 1443 & 1384 & 1402 & 1333 & 1326 & 1339 & 1344 & 19.3 & $* *$ & NS & NS \\
\hline $37 \mathrm{~d}$ & 1861 & 1916 & 1838 & 1864 & 1769 & 1781 & 1768 & 1801 & 25.9 & $* *$ & NS & NS \\
\hline $43 d$ & 2176 & 2228 & 2147 & 2201 & 2149 & 2082 & 2044 & 2105 & 39.3 & $* *$ & NS & NS \\
\hline \multicolumn{13}{|c|}{$\overline{\text { Weight gain (g) }}$} \\
\hline $23-30 \mathrm{~d}$ & 359.5 & 382.2 & 338.9 & 333.3 & 278.3 & 268.2 & 292.2 & 282.2 & 19.0 & $* *$ & NS & NS \\
\hline $30-37 d$ & 441.1 & 472.2 & 453.3 & 462.2 & 436.1 & 455.0 & 429.5 & 457.2 & 20.7 & NS & NS & NS \\
\hline $37-43 \mathrm{~d}$ & 314.5 & 312.2 & 308.9 & 337.0 & 380.6 & 300.6 & 276.1 & 303.9 & 32.1 & NS & NS & NS \\
\hline $23-43 d$ & 1115.0 & 1166.7 & 1101.1 & 1132.5 & 1095.0 & 1022.8 & 997.8 & 1043.4 & 38.8 & $*$ & NS & NS \\
\hline \multicolumn{13}{|c|}{ Feed intake per bird (g) } \\
\hline $23-30 \mathrm{~d}$ & 84.3 & 89.9 & 81.8 & 83.9 & 70.9 & 71.7 & 74.2 & 73.6 & 2.4 & $* *$ & NS & NS \\
\hline $30-37 \mathrm{~d}$ & 159.8 & 166.2 & 152.5 & 153.5 & 144.9 & 145.3 & 146.7 & 143.8 & 4.6 & $* *$ & NS & NS \\
\hline $37-43 \mathrm{~d}$ & 134.4 & 138.2 & 125.1 & 117.6 & 125.3 & 121.1 & 126.2 & 120.9 & 6.1 & NS & NS & NS \\
\hline $23-43 \mathrm{~d}$ & 107.2 & 110.5 & 101.4 & 100.2 & 96.6 & 94.8 & 97.4 & 95.6 & 2.8 & $* *$ & NS & NS \\
\hline \multicolumn{13}{|c|}{ Feed convertion ratio } \\
\hline $23-30 \mathrm{~d}$ & 1.645 & 1.674 & 1.716 & 1.784 & 1.789 & 1.889 & 1.802 & 1.862 & 0.08 & * & NS & NS \\
\hline $30-37 \mathrm{~d}$ & 2.576 & 2.472 & 2.373 & 2.329 & 2.330 & 2.236 & 2.429 & 2.240 & 0.10 & NS & NS & NS \\
\hline $37-43 \mathrm{~d}$ & 2.154 & 2.241 & 2.044 & 1.958 & 1.789 & 2.018 & 2.308 & 1.999 & 0.14 & NS & NS & NS \\
\hline $23-43 \mathrm{~d}$ & 2.024 & 1.995 & 1.941 & 1.870 & 1.883 & 1.948 & 2.052 & 1.928 & 0.06 & NS & NS & NS \\
\hline
\end{tabular}


Table 3: Effects of two dietary rice bran levels and balancing the diets for up to four amino acids on some carcass parameters of broiler chicken

\begin{tabular}{|c|c|c|c|c|c|c|c|c|c|c|c|c|}
\hline \multirow{2}{*}{$\begin{array}{l}\text { RB level } \\
\text { AA }\end{array}$} & \multicolumn{2}{|l|}{$20 \%$} & \multicolumn{5}{|c|}{$40 \%$} & \multicolumn{5}{|c|}{ Probability } \\
\hline & $\mathbf{L M}$ & LMI & LMIV & LMIVT & $\mathbf{L M}$ & LMI & LMIV & LMIVT & SEM & RB & $\mathbf{A A}$ & $\mathbf{R B} * \mathbf{A A}$ \\
\hline Tibia ash (\%) & 36 & 34 & 37 & 38 & 35 & 35 & 32 & 31 & 1.3 & $* * *$ & NS & $*$ \\
\hline Empty carcass (g) & 1540 & 1474 & 1527 & 1640 & 1584 & 1535 & 1442 & 1556 & 69 & NS & NS & NS \\
\hline Liver* & 4.0 & 4.9 & 3.7 & 3.8 & 2.8 & 2.4 & 2.3 & 2.0 & 0.3 & $* * *$ & NS & NS \\
\hline Gizzard* & 2.1 & 2.0 & 1.9 & 1.8 & 2.0 & 2.0 & 1.9 & 1.8 & 0.2 & NS & NS & NS \\
\hline Pancreas ${ }^{*}$ & 0.25 & 0.25 & 0.32 & 0.25 & 0.24 & 0.23 & 0.29 & 0.27 & 0.02 & NS & NS & NS \\
\hline Fat $(\%)$ & 2.98 & 2.99 & 2.21 & 2.27 & 2.36 & 1.73 & 2.31 & 2.07 & 0.3 & * & NS & NS \\
\hline
\end{tabular}

*as a $\%$ of empty carcass

Availability of AAs from RB for poultry is low due to several reasons such as complexing with phytic acids (Ravindran et al. 1995; Rutherford et al. 1997; Selle et al. 2000), negative effects of fibre (Warren and Farrell 1990) and anti-proteolytic substances (Kratzer and Chiaravanout 1974; Deolanker and Singh 1979; Tashiro and Maki 1979;. Mitsuda et al. 1977 ). It was assumed that balancing the diets for higher number, not only for methionine and lysine, but also for isoleucine, valine and threonine would improve the performance of broilers. At both RB levels balancing the diets for higher number of amino acids increased the levels of several amino acids than the requirement and dietary $\mathrm{CP}$ content by about 2 percentage units. Even under such a situation, rations balanced for higher number of AAs had no significant positive effect on any of the growth performance parameters. This suggests that even at $20 \%$ dietary RB level, balancing the rations for more amino acids has no beneficial effects on growth performance.

Absence of significant interaction between RB levels and the number of AAs considered in ration formulation suggests that adverse effects of higher dietary RB inclusion levels on growth performance of broiler chicken can not be mitigated by balancing diets for more amino acids.

Broilers inability to respond positively to higher AA levels may be due to two reasons. Adverse effects of RB on growth performance are attributed to a range of factors such as phytate, fibre and antiproteolytic substances. Balancing the rations for more AAs, at best addresses only the aspects related to low AA availability of RB. Therefore, even though balancing for more AAs improved the availability of AAs, the actions of other anti-nutrients might have exerted negative impacts overriding the positive effects of increased AA availability. This suggests the importance of addressing the problems bring about by many or all anti-nutrients present in RB simultaneously, if its inclusion level to be increased in poultry diets.

\section{Carcass parameters}

The lower tibia ash content of the birds fed $40 \%$ RB suggests that the availability of phosphorus was low. This may probably be due to the higher phytic
$\mathrm{P}$ contents of the rice bran. Interestingly, increase of the RB level from $20 \%$ to $40 \%$ significantly reduced the percentage weight of liver from 4.1 to $2.4 \%$. Furthermore, the percentage of the fat was also significantly reduced from 2.6 to 2.2 when dietary RB level was increased from 20 to $40 \%$. All diets were isocaloric and thus the additional amount of energy that deposited as fat might have generated at metabolic level. Since RB reduces the availability of AAs, the levels of AAs available for the metabolic utilization could be higher when $20 \%$ RB was fed. Since threonine became the limiting factor at both RB levels, it may be possible that more AAs might have left unutilized, deaminated and deposited as fat by the birds fed $40 \% \mathrm{RB}$. In other words, though the amount of AAs available for the utilization was low, the birds fed $40 \% \mathrm{RB}$ seem to have utilized them more effectively, than those fed $20 \%$ RB.

\section{CONCLUSION}

The results of this study suggest that broiler rations based on rice bran, soy, maize and sesame could be deficient in threonine and thus threonine should also be considered in ration formulation. Balancing rations for up to four amino acids; lysine, methionine, isoleucine and valine does not improve the performance nor mitigate the adverse effects of $40 \%$ dietary RB in broiler growth performance.

\section{ACKNOWLEDGEMENT}

The excellent technical assistance of Mr PK Lal and Mr MMK Premakumara is highly acknowledged.

\section{REFERENCES}

Atapattu NSBM and VLR Gamage 2007 Effects of supplementation of diets containing high levels of rice bran with microbial phytase on the performance of broiler chicken. Fourth Academic Sessions- University of Ruhuna. 9 
Deolanker RP and Singh KS 1979 Trypsin inhibitor, mineral availability, and performance of broiler chickens fed on diets based in rice bran. Animal Feed Science and technology. 4(2): 133 $-141$

Farrell DJ and Martin EA 1998a Strategies to improve the nutritive value of rice bran in poultry diets. 1 . The addition of food enzymes to target the non-starchy polysaccharide fraction in the diets of chicken and ducks gave no response. British Poultry Science. 39:549-554.

Farrell DJ and Martin EA 1998b Strategies to improve the nutritive value of rice bran in poultry diets III. The addition of inorganic phosphorous and a phytase to duck diets. British Poultry Science. 39:601-611.

Fernandez SR, Aoyagi S, Han Y, Parsons CM and DH Baker 1994 Limiting order of amino acids in corn and soybean meal for growth of the chick. Poultry Science. 73:1887-1896.

Kidd MT and Kerr BJ 1996 Threonine for poultry. Review. Journal of Applied Poultry Research. 5:358-367

Kidd MT 2000 Nutritional considerations concerning threonine in broilers. Worlds Poult. Sci. J. 56:139-151

Kratzer FS, Earl L and Chiaravanout C 1974 Factors affecting the feeding value of rice bran for chicken. Poultry Science. 53: 1795-1800.

Martin EA, Nolan JV, Nitsan Z and Farrell DJ 1998 Strategies to improve the nutritive value of rice bran in poultry diets. IV. Effects of addition of fish meal and microbial phytase to duckling diets on bird performance and amino acid digestibility. British Poultry Science 39:612-621

Mitsuda H, Yasumoto K and Yamamoto S 1977 Protein in rice bran and polish for human nutrition. In: S Barber and E Tortosa (eds). Proceedings of rice by products utilization. International conference. 1974. Valencia.

Ravindran V, Bryden WL and Kornegay ET 1995 Phytate: Occurrence, bioavailability and implications in poultry nutrition. Poultry and Avian Biology Review. 6:125-143.

Rutherford SM, Edwards ECE and Selle PH 1997 Effects of phytase on lysine-rich pollard complexes. In: Manipulating pig production, Vol 6. Cramwel PD (ed). Werriebee, Victoria, Australian Pig Science.

Selle PH, Ravindran V, Caldwell RA and Bryden WL 2000 Phytate and Phytase: Consequences for protein utilisation. Nutrition Research Review. 13:255-278

Tashiro M and Maki Z 1979 Purification and characterization of a trypsin inhibitor from rice Oriza sativa) bran. Journal of Natural Science and Vitaminolgy. 25:255-264.

Warren BE and Ferrell DJ 1990 The nutritive value of full-fat and defatted Australian rice bran II. Growth studies with chicken, rats and pigs. Animal Feed Science and Technology. 27:229246. 